УДК 618.33

DOI: $10.18101 / 2306-1995-2020-1-75-82$

\title{
АНАЛИЗ ЧАСТОТЫ ВЫЯВЛЕНИЯ ВРОЖДЕННЫХ ПОРОКОВ РАЗВИТИЯ У ПЛОДА ЗА ПОСЛЕДНИЕ 3 ГОДА
}

\section{(C) Нечунаева Александра Николаевна}

преподаватель кафедры акушерства и гинекологии

с курсом педиатрии

Бурятский государственный университет имени Доржи Банзарова

Россия, 670002, г. Улан-Удэ, ул. Октябрьская, 36а

alexandra907@mail.ru

\section{(C) Ботоева Елена Аполлоновна}

кандидат медицинских наук, доцент, заведующий кафедрой акушерства и гинекологии

с курсом педиатрии

Бурятский государственный университет имени Доржи Банзарова Россия, 670002, г. Улан-Удэ, ул. Октябрьская, 36а

elenabotoeva@list.ru.

\section{(C) Жовтун Людмила Марковна}

старший преподаватель кафедры акушерства и гинекологии

с курсом педиатрии

Бурятский государственный университет имени Доржи Банзарова

Россия, 670002, г. Улан-Удэ, ул. Октябрьская, 36а

zhovtun.lyudmila@mail.ru

Аннотация. Актуальность проблемы врожденных пороков развития (ВПР) трудно переоценить, невзирая на развитие методик пренатальной диагностики и достижений неонатологии, ВПР продолжают занимать первые места в структуре детской заболеваемости, смертности и инвалидности в развитых странах. Сложность данной проблемы заключается в ее разнородности: вместе с несомненным вкладом в цифры младенческой и детской смертности, врожденные пороки развития требуют длительного, часто пожизненного, лечения, хирургической коррекции, помощи в социальной адаптации детей, приводят к присваиванию таким детям статуса инвалидов. В индивидуальную программу реабилитации инвалидов включаются медицинская реабилитация, реконструктивная хирургия, протезирование и ортезирование, санаторно-курортное лечение, а по показаниям - технические средства и услуги, предоставляемые инвалиду за счет средств федерального бюджета. Кроме того, ВПР оказывают сильнейшее психоэмоциальное воздействие на семьи, становятся причиной отказа от детей, разво- 
дов, и формируют социально-экономическое бремя, ложащееся на государство, в частности, на систему здравоохранения. Как известно, профилактика врожденных пороков развития в последние десятилетия стала одним из приоритетных направлений медицинской науки. Наиболее эффективным способом решения проблемы является прогнозирование и коррекция факторов риска возникновения ВПР в потомстве путем работы с родителями, организации доступной системы своевременного медикогенетического консультирования, санитарно-просветительская работа, усиление работы службы санитарно-гигиенического надзора.

Объектом исследования послужили данные «ГБУЗ Женская консультация №1». Предметом исследования стала частота пренатально выявленных и подтвержденных пороков развития за 2017-2019 гг.,

Ключевые слова: ВПР; пренатальная диагностика; ультразвуковое исследование.

\section{Для цитирования}

Нечунаева А. Н., Ботоева Е. А., Жовтун Л. М. Анализ частоты выявления врожденных пороков развития у плода за последние 3 года // Вестник Бурятского государственного университета. Медицина и формация. 2020. Вып. 1. С. 75-82.

\section{Введение}

Антенатальная патология была и остается одной из наиболее актуальных проблем в структуре современной медицинской науки в связи со значительным вкладом, вносимым ей в цифры детской и младенческой смертности, частными и государственными затратами на лечение и реабилитацию, более чем в половине случаев не оправдывающимися вследствие низкой жизнеспособности таких детей, а также чрезвычайной распространенностью и клиническим полиморфизмом ВПР, что часто затрудняет своевременную диагностику как на пре-, так и постнатальном этапе $[1 ; 4]$.

Антенатальной патологией в настоящий момент называют все виды отклонений нормального развития зародыша в период от момента образования зиготы до начала родов, а врожденные пороки развития (ВПР), соответственно, считаются ее типичным проявлением. Под врожденными пороками развития следует понимать грубые анатомические нарушения органов и/или тканей (системы органов), приводящие к расстройствам их функций. [2; 3; 8].

\section{Материал и методы исследования}

Был произведен анализ встречаемости и особенностей диагностики врожденных пороков развития по данным женской консультации №1 города Улан-Удэ за последние 3 года. 
А. Н. Нечунаева, Е. А. Ботоева, Л. М. Жовтун. Анализ частоты выявления врожденных пороков развития у плода за последние 3 года

В 2017 году при помощи УЗИ скрининга пренатально было диагностировано 7 аномалий развития, из которых постнатально подтвердилось только 4. В 2018 показатели составили 9 диагностированных пороков развития и 6 подтвержденных. В 2019 году при помощи УЗ-скрининга врожденные пороки были диагностированы у 19 детей, из которых этот диагноз не подтвердился только у 2 пациентов. Подобные случаи ложного диагноза ВПР могут быть обусловлены трудностями в диагностике или же некоторой задержкой внутриутробного развития. Неблагоприятные исходы наблюдались в 3 случаях: 1 случай в 2017 году и 2 случая в 2019. При этом дети погибали во время родов или в течение первой недели жизни.

Таблица 1

Количество диагностированных и подтвержденных ВПР

\begin{tabular}{|l|c|c|c|}
\hline \multicolumn{1}{|c|}{ Показатель } & 2017 & 2018 & 2019 \\
\hline $\begin{array}{l}\text { Количество пороков развития, диагности- } \\
\text { рованных пренатально }\end{array}$ & 7 & 9 & 19 \\
\hline $\begin{array}{l}\text { Количество подтвержденных врожденных } \\
\text { пороков развития, \% }\end{array}$ & 57 & 67 & 89 \\
\hline $\begin{array}{l}\text { Смертность от ВПР, \% от всех подтвер- } \\
\text { жденных пороков. }\end{array}$ & 25 & 0 & 12 \\
\hline
\end{tabular}

Известно, что возраст старше 35 лет считается одним из ведущих факторов изменения кариотипа эмбриона. Для оценки возраста как фактора риска формирования врожденных пороков развития было решено разделить всех беременных на две группы. Группа женщин младше 30 лет составила 12 человек, группа пациенток от 30 лет и старше - 15 человек. Учитывая вышесказанное, логичным представляется предположение о том, что вместе со значением возраста будет возрастать величина выявленных пороков развития у плода. Таким образом, процент женщин, чьим детям был выставлен диагноз «ВПР», до 30 лет составил 44\%, в то время как процент женщин после 30 лет - 56\%, что прямым образом подтверждает тенденцию к возрастанию частоты ВПР вместе с увеличением возраста матерей.

Пренатальная диагностика врожденных пороков развития включает в себя проведение биохимического скрининга для оценки риска хромосомных аномалий, а также проведение 3-х УЗИ-скринингов, по одному на каждый триместр беременности [5,8]. Согласно полученным данным 2017 год характеризовался наиболее полным охватом матерей скрининговыми исследованиями. Однако почти половина женщин в 2018 году и около четверти - в 2019 пропустили биохимический и первый ультразвуковой 
скрининговые этапы, при этом второй и третий диагностические УЗИскрининги прошли почти все.

Таблица 2

Охват женщин методами пренатальной диагностики

\begin{tabular}{|l|c|c|c|}
\hline \multicolumn{1}{|c|}{ Показатель } & 2017 & 2018 & 2019 \\
\hline $\begin{array}{l}\text { Количество подтвержденных врожденных поро- } \\
\text { ков развития }\end{array}$ & 4 & 6 & 17 \\
\hline $\begin{array}{l}\text { Доля матерей, прошедших биохимический скри- } \\
\text { нинг, \% }\end{array}$ & 100 & 67 & 71 \\
\hline $\begin{array}{l}\text { Доля матерей, прошедших первый УЗИ-скрининг, } \\
\%\end{array}$ & 100 & 50 & 77 \\
\hline $\begin{array}{l}\text { Доля матерей, прошедших второй УЗИ-скрининг, } \\
\%\end{array}$ & 75 & 100 & 100 \\
\hline $\begin{array}{l}\text { Доля матерей, прошедших третий УЗИ-скрининг, } \\
\%\end{array}$ & 100 & 100 & 94 \\
\hline
\end{tabular}

Согласно полученным данным, высокий риск развития врожденных аномалий по данным биохимического скрининга наблюдался только в одном случае в 2019 году. Почти половина всех аномалий развития были диагностированы во время второго обследования, при первом УЗИскрининге было диагностировано только 2 врожденных порока. Около трети пороков развития были впервые выявлены при третьем скрининге, а 3 порока оказались диагностированы только постнатально.

Таблица 3

Роль скрининговых методов в диагностике ВПР

\begin{tabular}{|l|c|c|c|}
\hline \multicolumn{1}{|c|}{ Показатель } & 2017 & 2018 & 2019 \\
\hline $\begin{array}{l}\text { Высокий риск аномалий развития по данным б/х } \\
\text { скрининга, \% }\end{array}$ & 0 & 0 & 6 \\
\hline $\begin{array}{l}\text { Врожденные пороки развития, диагностированные } \\
\text { при первом УзИ-скрининге, \% }\end{array}$ & 0 & 0 & 12 \\
\hline $\begin{array}{l}\text { Врожденные пороки развития, диагностированные } \\
\text { при втором УзИ-скрининге, \% }\end{array}$ & 50 & 83 & 35 \\
\hline $\begin{array}{l}\text { Врожденные пороки развития, диагностированные } \\
\text { при третьем УзИ-скрининге, \% }\end{array}$ & 50 & 17 & 35 \\
\hline Пороки, не диагностированные пренатально, \% & 0 & 0 & 18 \\
\hline
\end{tabular}

Было установлено, что в структуре врожденных пороков развития в исследуемый период наиболее часто встречались пороки мочевыделительной системы (в 11 случаях из 27), на втором месте по частоте находятся пороки сердечно-сосудистой системы (6 случаев), и на третьем пороки ЦНС (4 диагностированных порока). Множественные пороки развития были диагностированы только в одном случае. 
А. Н. Нечунаева, Е. А. Ботоева, Л. М. Жовтун. Анализ частоты выявления врожденных пороков развития у плода за последние 3 года

Таблица 4

Структура ВПР по пораженным системам

\begin{tabular}{|l|c|c|c|c|}
\hline \multicolumn{1}{|c|}{ Система } & 2017 & 2018 & 2019 & Всего \\
\hline Сердечно-сосудистая система, \% & 25 & 0 & 29 & 22,2 \\
\hline Центральная нервная система, \% & 25 & 17 & 12 & 14,8 \\
\hline Дыхательная система, \% & 25 & 0 & 6 & 7,4 \\
\hline Мочевыделительная система, \% & 25 & 33 & 47 & 40,8 \\
\hline Опорно-двигательная система, \% & 0 & 33 & 0 & 7,4 \\
\hline Челюстно-лицевой аппарат, \% & 0 & 17 & 0 & 3,7 \\
\hline Множественные пороки, \% & 0 & 0 & 6 & 3,7 \\
\hline
\end{tabular}

Полученные данные можно соотнести с общенациональной тенденции к увеличению частоты регистрации пороков мочевыделительной системы, что может быть результатом ухудшения экологической обстановки и воздействием неблагоприятных факторов урбанизации.

Анализ по полу показал, что в структуре заболеваемости ВПР врожденные аномалии не имели существенной зависимости от пола. Так, в 2017 году среди детей с подтвержденными ВПР было 2 мальчика и 2 девочки; в 2018 году: 4 мальчика, 2 девочки; в 2019 году - 8 мальчиков, 9 девочек.

\section{Заключение}

Настоящее эпидемиологическое исследование проводилось на основе характеристики частоты, структуры, динамики врожденных пороков развития среди населения советского района города Улан-Удэ за 2017-2019 гг. с целью предоставления достоверных данных о состоянии проблемы ВПР на указанной территории.

Для последовательного решения задач исследования были проанализированы данные о выявляемости ВПР за указанный период времени среди новорожденных, основой для изучения стали сведения о ВПР среди новорожденных за 3-летний период. Так, за 2017 год было подтверждено 4 случая, за 2018 год 6 случаев, за 2019 год - 17 случаев, что демонстрирует прогрессивное увеличение значений с течением времени, что может быть связано с ухудшением экологической обстановки в регионе и увеличением охвата пренатальными скринингами населения.

Также была оценена эффективность генетико-профилактических мероприятий на основании данных о пройденных матерями пренатальных скринингах, показавшая наиболее полный охват в 2017 году, но увеличение количества подтвержденных случаев в 2019 году. Кроме того, было выяснено, что нет значительных различий в охвате скринингами между жителями городской и сельской местности нет особых различий в при- 
верженности диагностическим мероприятиям. Между тем, наибольшую диагностическую ценность представил второй скрининг.

Отслежена корреляция между частотой ВПР и возрастом матерей, продемонстрировавшая, что более высокие значения выявленных и подтвержденных пороков развития регистрируются в группе матерей старше 30 лет.

Таким образом, в качестве вывода представляется необходимым отметить, что многолетние эпидемиологические исследования могут быть эффективными в обнаружении предотвратимых факторов риска формирования врожденных пороков развития. Подчеркнута роль пренатальной диагностики в профилактике формирования аномалий развития, а также установлены приоритетные направления диагностического поиска в процессе осуществления пренатальных скринингов - женщины старше 30 лет, особое внимание при осуществлении скрининговых исследований должна привлекать мочевыделительная система.

Частичное или полное нарушение здоровья детей вследствие ВПР требует больших материальных затрат и является одной из причин снижения рождаемости - многие семейные пары отказываются от рождения вторых и последующих детей [6,7]. Каждый родившийся ребенок с ВПР требует специальной хирургической коррекции, не всегда приводящей к эффективному результату, и продолжительной реабилитации для восстановления функции пораженного органа. В этой связи на первый план выходят мероприятия, направленные на предупреждение рождения детей с ВПР и снижение частоты пороков развития и популяции.

\section{Литература}

1. Бадалян А. О., Вельтищев Е. Ю., Таболин В. А. Наследственные болезни у детей. М.: Медицина, 1987. 268 с.

2. Пренатальная диагностика наследственных болезней. Состояние и перспективы / В. С. Баранов [и др.]. 2-е изд. СПб.: Эко-Вектор, 2017. 471 с.

3. Барашнев Ю. И., Бахарев В. А., Новиков П.В. Диагностика и лечение врожденных и наследственных заболеваний у детей. М.: Триада-X, 2004. C. $12-87$.

4. Неонатология (национальное руководство) / под ред. Н. Н. Володина. М.: Академия, 2008. 848 с.

5. Основы перинатологии / под ред. Н. П. Шабалова, Ю. В. Цвелева. М.: МЕДпресс-информ, 2002. С.24-158.

6. Пренатальная диагностика наследственных и врожденных болезней / под ред. Э. К. Айламазяна, В. С. Баранова. М.: Триада-Х, 2007. С. 111148. 
А. Н. Нечунаева, Е. А. Ботоева, Л. М. Жовтун. Анализ частоты выявления врожденных пороков развития у плода за последние 3 года

7. Самчук П. М., Ищенко А. И., Розалиева Ю. Ю. Органосохраняющие технологии при гнойных воспалительных осложнениях кесарева сечения // Вопросы гинекологии, акушерства и перинатологии. 2020. № 19(2). С. 69-103.

8. Самчук П. М., Азоева Э. Л., Розалиева Ю. Ю. Плацентарные нарушения при беременности, после реконструктивных операций на матке // Международный научно-исследовательский журнал. 2019. № 12(90). C. $215-220$.

9. Шабалов Н. П. Неонатология. СПб.: Спец. лит, 2006. С. 26-65.

\section{ANALYSIS OF THE FREQUENCY OF DETECTION \\ OF CONGENITAL MALFORMATIONS IN THE FETUS OVER THE PAST 3 YEARS.}

Nechunaeva A. Nikolaevna

teacher of the Department of obstetrics and gynecology

with a course in Pediatrics

Dorzhi Banzarov Buryat State University

36A Oktyabrskaya str., Ulan-Ude, 670002, Russia

alexandra907@mail.ru

Botoeva E. Apollonova

candidate of medical sciences, associate Professor, head of the Department of obstetrics and gynecology

with a course in Pediatrics

Dorzhi Banzarov Buryat State University

36A Oktyabrskaya str., Ulan-Ude, 670002, Russia

elenabotoeva@list.ru

Zhovtun L. Markovna

Senior lecturer of the Department of obstetrics and gynecology

with a course in Pediatrics

Dorzhi Banzarov Buryat State University

36A Oktyabrskaya str., Ulan-Ude, 670002, Russia

zhovtun.lyudmila@mail.ru

Abstract. It is difficult to overestimate the Relevance of the problem of congenital malformations - despite the development of prenatal diagnostics techniques and the achievements of neonatology, HRV continues to occupy the first places in the structure of child morbidity, mortality and disability in developed countries.

The complexity of this problem lies in its heterogeneity: along with the undoubted contribution to the figures of infant and child mortality, congenital malformations 
require long-term, often lifelong, treatment, surgical correction, assistance in social adaptation of children, and lead to the assignment of such children with the status of disabled people. The individual rehabilitation program for the disabled (IPR) includes medical rehabilitation, reconstructive surgery, prosthetics and orthoses, Spa treatment, and, if indicated, technical means and services provided to the disabled person at the expense of the Federal budget.

In addition, VPR has a strong psychoemotional impact on families, causes abandonment of children, divorce, and forms a socio-economic burden on the state, in particular, on the health care system.

As you know, prevention of congenital malformations in recent decades has become one of the priority areas of medical science. The most effective way to solve the problem is to predict and correct the risk factors for HPV in offspring by working with parents, organizing an accessible system of timely medical and genetic counseling, sanitary education, and strengthening the work of the sanitary and hygienic supervision service.

The object of the study was the data "GBUZ Women's consultation No. 1". The subject of the study was the frequency of prenatally detected and confirmed malformations in 2017-2019,

Keywords: HRV; prenatal diagnostics; ultrasound. 